\title{
Reciprocal changes in DNA methylation and hydroxymethylation and a broad repressive epigenetic switch characterize $F M R 1$ transcriptional silencing in fragile $X$ syndrome
}

Sarah Brasa ${ }^{1}$, Arne Mueller', Sébastien Jacquemont ${ }^{2}$, Florian Hahne ${ }^{1}$, Izabela Rozenberg ${ }^{3}$, Thomas Peters ${ }^{4}$, Yunsheng He ${ }^{4}$, Christine McCormack ${ }^{5}$, Fabrizio Gasparini ${ }^{6}$, Salah-Dine Chibout ${ }^{1}$, Olivier Grenet ${ }^{1}$, Jonathan Moggs ${ }^{1}$, Baltazar Gomez-Mancilla ${ }^{3^{*}}$ and Rémi Terranova ${ }^{1 *}$

\begin{abstract}
Background: Fragile X syndrome (FXS) is the most common form of inherited intellectual disability, resulting from the loss of function of the fragile X mental retardation 1 (FMR1) gene. The molecular pathways associated with FMR1 epigenetic silencing are still elusive, and their characterization may enhance the discovery of novel therapeutic targets as well as the development of novel clinical biomarkers for disease status.
\end{abstract}

Results: We have deployed customized epigenomic profiling assays to comprehensively map the FMR1 locus chromatin landscape in peripheral mononuclear blood cells (PBMCs) from eight FXS patients and in fibroblast cell lines derived from three FXS patient. Deoxyribonucleic acid (DNA) methylation (5-methylcytosine (5mC)) and hydroxymethylation (5hydroxymethylcytosine $(5 \mathrm{hmC})$ ) profiling using methylated DNA immunoprecipitation (MeDIP) combined with a custom FMR1 microarray identifies novel regions of DNA (hydroxy)methylation changes within the FMR1 gene body as well as in proximal flanking regions. At the region surrounding the FMR1 transcriptional start sites, increased levels of $5 \mathrm{mC}$ were associated to reciprocal changes in 5hmC, representing a novel molecular feature of FXS disease. Locus-specific validation of FMR1 $5 \mathrm{mC}$ and $5 \mathrm{hmC}$ changes highlighted inter-individual differences that may account for the expected DNA methylation mosaicism observed at the FMR1 locus in FXS patients. Chromatin immunoprecipitation (ChIP) profiling of FMR1 histone modifications, together with $5 \mathrm{mC} / 5 \mathrm{hmC}$ and gene expression analyses, support a functional relationship between $5 \mathrm{hmC}$ levels and FMR1 transcriptional activation and reveal cell-type specific differences in FMR1 epigenetic regulation. Furthermore, whilst 5mC FMR1 levels positively correlated with FXS disease severity (clinical scores of aberrant behavior), our data reveal for the first time an inverse correlation between 5hmC FMR1 levels and FXS disease severity.

Conclusions: We identify novel, cell-type specific, regions of FMR1 epigenetic changes in FXS patient cells, providing new insights into the molecular mechanisms of FXS. We propose that the combined measurement of $5 \mathrm{mC}$ and $5 \mathrm{hmC}$ at selected regions of the FMR1 locus may significantly enhance FXS clinical diagnostics and patient stratification.

Keywords: Fragile X syndrome (FXS), Chromatin profiling, Epigenetic silencing, FMR1, 5-hydroxymethylation (5hmC), Clinical biomarker

\footnotetext{
*Correspondence: baltazar.gomezmancilla@novartis.com; remi.terranova@ novartis.com

${ }^{3}$ Neuroscience Translational Medicine, Novartis Institutes for Biomedical Research, Novartis Pharma AG, CH-4056 Basel, Switzerland

${ }^{1}$ Preclinical Safety, Translational Medicine, Novartis Institutes for Biomedical

Research, Novartis Pharma AG, CH-4057 Basel, Switzerland

Full list of author information is available at the end of the article
} 


\section{Background}

Fragile X syndrome (FXS) is the most common inherited form of mental retardation and autism in males $[1,2]$. The syndrome is commonly associated with the expansion of cytosine-guanine-guanine (CGG) trinucleotide repeats in the $5^{\prime}$ untranslated region (5'UTR) of the human fragile $\mathrm{X}$ mental retardation 1 (FMR1) gene. In patients with more than 200 CGG repeats, the aberrant, CGG-repeat expanded FMR1 messenger ribonucleic acid (mRNA) mediates FMR1 gene silencing [3] resulting in the absence of fragile X mental retardation protein (FMRP) expression, a translational regulator involved in neurotransmitter mediated synaptic maturation and plasticity [2]. Premutation carriers of FXS display a varying number of CGG repeats (55-200) associated with either normal or mild deficits in the expression of the FMR1 gene $[4,5]$. Despite two decades of studying the (epi)genetic dynamics of the FMR1 locus, little is known about the molecular events and pathways that lead to FMR1 silencing in individuals carrying a full-mutated $(>200$ CGG repeats) allele. Aberrant deoxyribonucleic acid (DNA) hypermethylation of the FMR1 promoter CpG island and CGG repeats is strongly associated with FMR1 gene silencing and represents a molecular hallmark of full-mutation FXS patients [6-11]. The acquisition of DNA methylation at the FMR $1 \mathrm{CpG}$ island is accompanied by hypoacetylation of associated histones and acquisition of repressive histone post-translational modifications such as the methylation of the lysine 9 of histone $\mathrm{H} 3$ (H3K9me) and chromatin condensation, all characteristics of a transcriptionally inactive gene [12-15]. The methylation status of FMR1 in fullmutation patients can vary across cell types (methylation mosaicism) and is significantly associated with the clinical phenotype of FXS patients [5, 16-20]. The methylation observed at the FMR1 CpG island extends beyond the FMR1 promoter and spreads into the first intron [21, 22]. A small number of full-mutation, unmethylated individuals have also been reported [23]. These patients displayed a FMR1 promoter epigenetic pattern comparable to that of normal controls, in accordance with normal transcription levels and consistent with a euchromatic configuration. The mechanisms preventing the initial methylation and protecting against a repressive chromatin configuration are unknown, and their identification may help understand the key pathways affected in the majority of full-mutation patients and might ultimately lead to new therapeutic opportunities for restoring normal FMR1 expression levels in FXS patients [12, 24].

DNA hydroxymethylation (5-hydroxymethylcytosine $(5 \mathrm{hmC}))$, a DNA methylation (5-methylcytosine $(5 \mathrm{mC})$ ) derivative was rediscovered in mouse Purkinje cells and granule neurons $[25,26]$. These newly characterized epigenetic marks are catalyzed by a group of enzymes belonging to the ten-eleven translocation methylcytosine dioxygenase (TET) family (TET 1, 2, and 3) [27]. The
$5 \mathrm{hmC}$ mark is distributed over the promoter and bodies of transcriptionally active genes as well as enhancer elements [28-30] and may both represent an epigenetic modification in its own right and also an intermediate product in an active DNA demethylation pathway, accounting for the maintenance of DNA demethylation at CpG-rich promoters [27, 31]. $5 \mathrm{hmC}$ is particularly enriched in the central nervous system where it may play specific and dynamic functions in the regulation of gene expression [32] including regulation of alternative splicing as well as synaptic function in the brain [33]. The distribution of $5 \mathrm{hmC}$ is dynamically regulated during neurodevelopment, it may play a role in a number of neurodegenerative diseases [34, 35] and is also perturbed in an animal model of Rett syndrome, a neurodevelopmental disorder caused by a mutation in the MeCP2 gene which encodes a $5 \mathrm{mC}$ and a $5 \mathrm{hmC}$ binding protein which targets transcriptional activation or repression functions to its binding sites [32, 36, 37].

In the present study, we have used broad epigenomic profiling of the FMR1 locus (beyond the well-characterized promoter/CpG island regions) to identify novel epigenetic marks and mechanisms that may contribute to FMR1 silencing in blood-derived FXS full-mutation patients samples. We have integrated FMR1 locus-specific methylation $(5 \mathrm{mC}$ and $5 \mathrm{hmC}$ ), histone post-translational modifications, and gene expression with clinical scores of aberrant behavior in a group of eight FXS patients. Our data reveal novel molecular-clinical phenotype associations that may provide novel diagnostic tools for the prediction and stratification of FXS disease severity.

\section{Results}

(hydroxy)-MeDIP profiling identifies novel regions of $5 \mathrm{mC}$ and $5 \mathrm{hmC}$ changes in the FMR1 locus of FXS patient blood samples

(hydroxy-)methylated DNA immunoprecipitation assays, (h)MeDIP, were used to investigate the DNA methylation $(5 \mathrm{mC})$ and hydroxymethylation $(5 \mathrm{hmC})$ landscape of the broader FMR1 locus in peripheral blood mononuclear cells (PBMC) samples from eight fragile $\mathrm{X}$ syndrome patient and four control individual samples (Fig. 1a). The age, ABC clinical score, FMR1 CGG repeat size, and FMR1 expression for each patient are indicated in Additional file 1: Table S1, alongside locus specific measurement for each epigenetic mark investigated in this study. Input and (h)MeDIP-enriched fractions were labeled and applied onto a custom designed array covering the entire FMR1 genomic region on chromosome X (hg19, ChrX: 146,911,760-147,159,387: summarized in the "Methods" section).

Analyses of the $5 \mathrm{mC}$ profile using a genome visualization tool detected the expected DNA hypermethylation at an estimated 3.8-kb-long region surrounding 


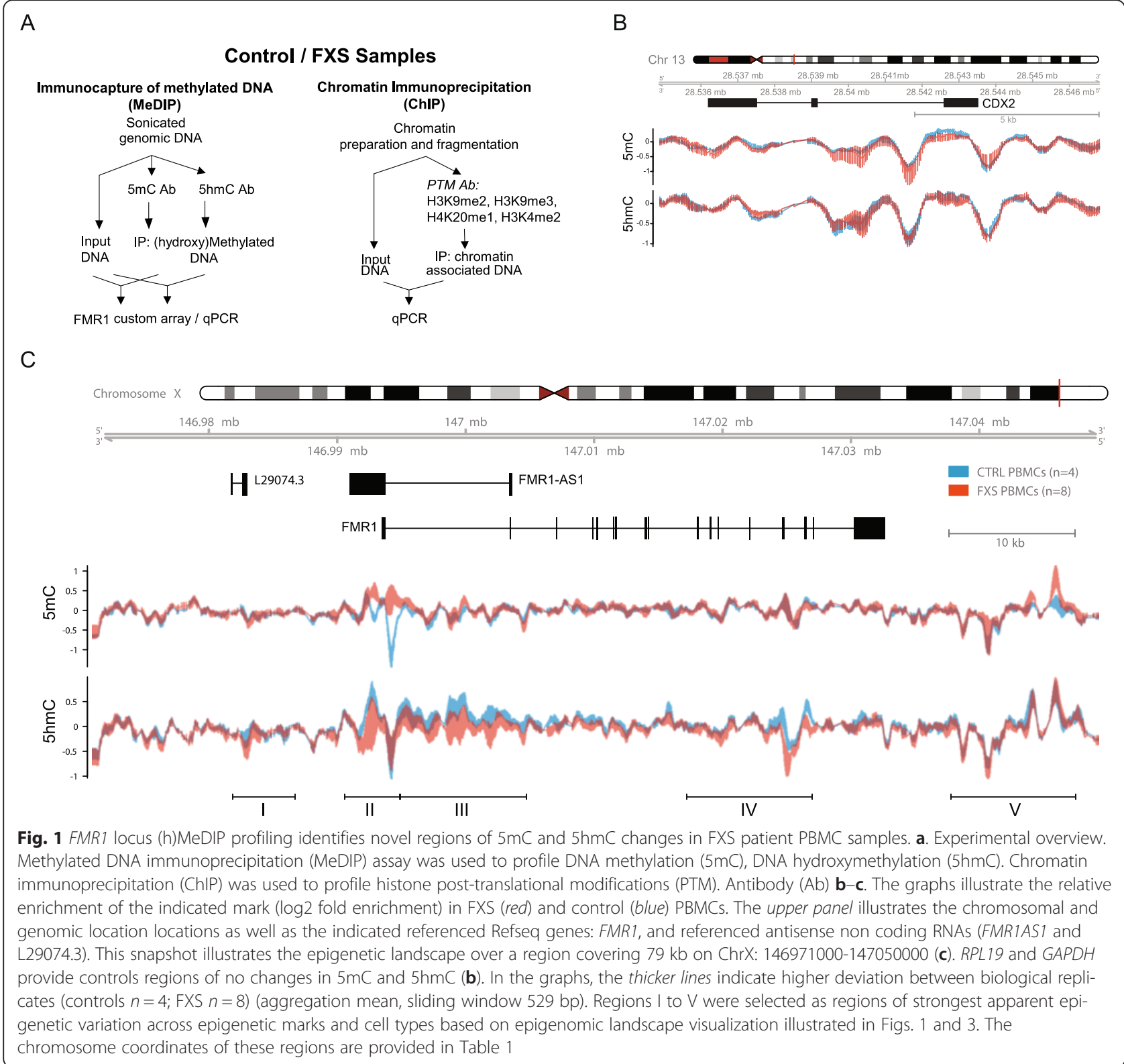

the transcriptional start site of FMR1 in FXS PBMC (region II covering $-3.5 \mathrm{~kb} /+0.3 \mathrm{~kb}$ of the FMR1 start site, ChrX: 146,990,000-146,993,800) (Fig. 1c, Table 1). An additional region of DNA hypermethylation was an apparent downstream of FMR1 coding region (region V). These signatures are observed by MeDIP array across all individual PBMC samples (Fig. 1c, Table 1) and identify novel regions of DNA methylation perturbation in FXS patient samples.

The profiling of hydroxymethylated DNA in PBMC samples revealed broad $5 \mathrm{hmC}$ perturbations in FXS patient samples. Hydroxymethylated CpGs are typically found at transcribed gene bodies, active enhancers, and at a limited cohort of annotated transcriptional start site (TSS) [28-30].
Interestingly, our analyses revealed $5 \mathrm{hmC}$ enrichment in control over FXS samples within four FMR1 locus genomic regions located (1) upstream of FMR1, (2) at the TSS, (3) throughout the first intron, and (4) in a region located between introns 13 and 16 (Fig. 1c, Table 1), highlighting FMR1 hypo-hydroxymethylation as a novel features of fragile $\mathrm{X}$ syndrome. To validate the specificity of FMR1 DNA (hydroxy)methylation perturbations, additional control genomic regions were investigated from the array data and validated by (h)MeDIP-PCR and did not display differential $5 \mathrm{mC} / 5 \mathrm{hmC}$ distribution or enrichment in healthy controls and FXS samples (Fig. 1b, Additional file 2: Figure S1C and Additional file 3: Figure $\mathrm{S} 2 \mathrm{C}$ ). 
Table 1 Chromosomal coordinates of regions of FMR1 epigenetic variability in FXS cells. The major regions or FMR1 epigenetic changes identified in FXS PBMCs and fibroblasts (Figs. 1 and 3). Each region is indicated with a unique ID. The functional location (relative to the transcriptional start site (TSS)/untranslated regions (UTR)), chromosome coordinates, and estimated size of the region of perturbation are indicated

\begin{tabular}{|c|c|c|c|}
\hline Region ID & Functional genomic location & Chromosome coordinates & Size (kb) \\
\hline \multirow[t]{2}{*}{ Region I } & Upstream—L29074.3 & ChrX: 146981500-146986000 & 4.5 \\
\hline & TSS $-12 \mathrm{~kb} /-7.5 \mathrm{~kb}$ & & \\
\hline \multirow[t]{2}{*}{ Region II } & Promoter-intron 1 & ChrX: 146990000-146993800 & 3.8 \\
\hline & TSS -3.5 kb/+0.3 kb & & \\
\hline \multirow[t]{2}{*}{ Region III } & Intron1 & ChrX: 146993800-147004000 & 9.9 \\
\hline & $\mathrm{TSS}+0.3 \mathrm{~kb} /+10.2 \mathrm{~kb}$ & & \\
\hline \multirow[t]{2}{*}{ Region IV } & Gene body-introns 12-16 & ChrX: 147018000-147028000 & 10 \\
\hline & TSS +24.5 kb/34.5 kb & & \\
\hline \multirow[t]{2}{*}{ Region V } & Downstream & ChrX: 147038000-147048000 & 10 \\
\hline & $3^{\prime} \mathrm{UTR}+6.1 \mathrm{~kb} /+15.3 \mathrm{~kb}$ & & \\
\hline
\end{tabular}

Overall, our analyses identify novel regions of $5 \mathrm{mC}$ changes along FMR1 and beyond the regions already described outside of the promoter/first intron regions [21]. Our data also describe for the first time broad changes in FMR1 $5 \mathrm{hmC}$ levels and distribution in FXS PBMCs, highlighting novel molecular features that may be associated with FMR1 epigenetic regulation in fragile $\mathrm{X}$ syndrome patient cells.

\section{Inter-individual variations in FMR $15 \mathrm{mC}$ and $5 \mathrm{hmC}$ changes in FXS PBMC}

Next, we developed novel locus-specific (h)MeDIP-PCR assays based on the identification of novel regions of (hydroxy)methylation ( $5 \mathrm{mC}$ and $5 \mathrm{hmC}$ ) changes in FXS PBMC-derived DNA samples. Our results (Fig. 2a) confirmed significant increase of $5 \mathrm{mC}$ levels at proximity of FMR1 TSS. Further discrete $5 \mathrm{mC}$ perturbations are observed in the FMR1 gene body with moderate decrease in $5 \mathrm{mC}$ levels within the alternative-splicing rich region (region IV, detected with 3F9G1 assay) spanning FMR1 exon 15 [36, 37], and a moderate increase $10 \mathrm{kbp}$ downstream of the FMR1 3'UTR (region V, detected with assay 3H78). On the other hand, $5 \mathrm{hmC}$ was significantly decreased throughout the FMR1 locus with broader changes taking place at the promoter region and through the entire FMR1 first intron, validating in a semi-quantitative, independent manner the array-based identification of novel regions of FMR $15 \mathrm{mC}$ and $5 \mathrm{hmC}$ changes in FXS PBMCs. Interestingly, PCR validation highlighted important interindividual variations in $5 \mathrm{hmC}$ levels across FXS patient samples in most interrogated regions, representing potential inter-individual differences in FMR1 epigenetic regulation and/or highlighting FMR1 genetic/transcriptional mosaicism in a population of FXS patient PBMCs (Additional file 2: Figure $\mathrm{S} 1$ and Additional file 3: Figure S2). The comparison of $5 \mathrm{mC}$ and $5 \mathrm{hmC}$ MeDIP-array data from individual patients (Fig. 2b) to locus specific $5 \mathrm{mC}$ (MeDIP-PCR and pyrosequencing) and $5 \mathrm{hmC}$ (hMeDIPPCR) (Fig. 2a, c) reveals consistent patterns of $5 \mathrm{mC} / 5 \mathrm{hmC}$ levels at the TSS region where $5 \mathrm{mC} / 5 \mathrm{hmC}$ changes are most evident. Amongst the analyzed FXS samples, samples from patients B and E (arrowed) show healthy control levels of $5 \mathrm{hmC}$ while samples from patients $\mathrm{C}$ and $\mathrm{F}$ display the strongest reduction in $5 \mathrm{hmC}$, both with arrayand PCR-based readouts. Interestingly, these two patients are also characterized by mosaic CGG repeat, the highest FMR1 expression levels, and the lowest reported clinical scores (Additional file 1: Table S1) highlighting the correlation between molecular and phenotypic data (see Fig. 5). Importantly, the comparison of $5 \mathrm{mC}$ and $5 \mathrm{hmC}$ points to anti-correlation between the two epigenetic marks (Fig. 2a, $\mathrm{c}$, arrows). Our data highlight broad $5 \mathrm{hmC}$ level changes across the FMR1 locus of FXS patients PBMCs together with reciprocal $5 \mathrm{mC} / 5 \mathrm{hmC}$ changes at the FMR1 TSS region suggesting that combined measurement of $5 \mathrm{mC}$ and $5 \mathrm{hmC}$ may provide enhanced molecular and functional characterization of FXS patient samples.

\section{Changes in $5 \mathrm{mC}$ and $5 \mathrm{hmC}$ associate with broad changes in the FMR1 locus histone post-translational modification landscape in FXS patients}

To further investigate the molecular features underlying FMR1 silencing in FXS and select markers of interest to be evaluated in clinical FXS PBMC samples, we carried out chromatin immunoprecipitation (ChIP) using antibodies for histone post-translational modifications (PTM) associated to gene repression (H3K27me3, H3K9me2, H3K9me3) and gene activation (H3K36me3, H3K4me2, H3K9ac, H4K16ac, H4K20me1) on chromatin from three FXS fibroblasts lines (Coriell GM05848 fibroblasts from a 4-year-old patient, GM07072 fetal lung fibroblasts from 22-week-old fetus, and GM09497 fibroblasts from a 28-year-old FXS 
A

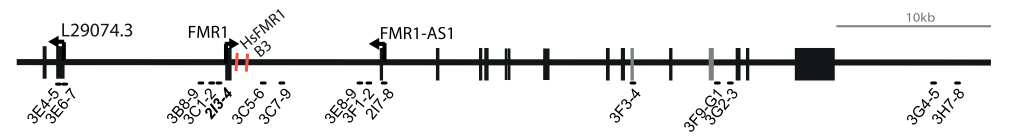

2/3-4

TSS $-604 b p$
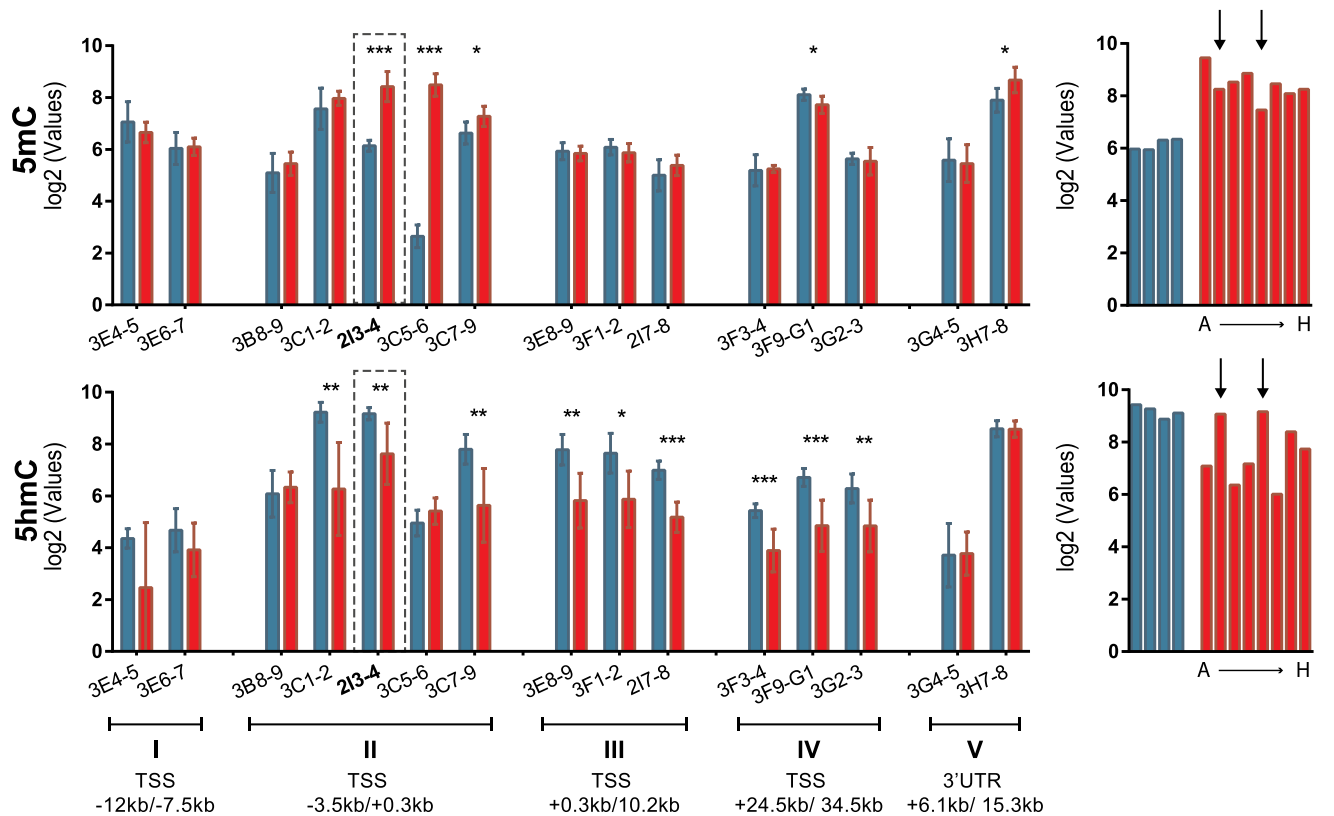

B

$$
5 \mathrm{mC}
$$

FMR1

ChrX:146990500-147001000 (10.5kb)

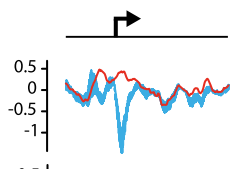

Patient B

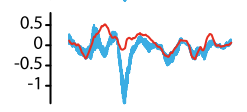

Patient C

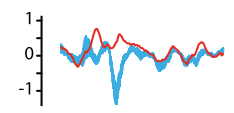

Patient D

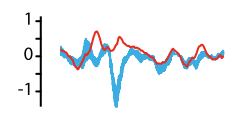

Patient E

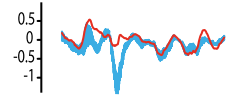

Patient $F$

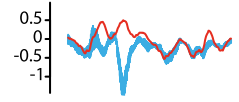

Patient G

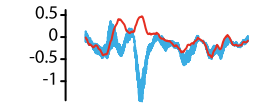

Patient $\mathrm{H}$
$5 \mathrm{hmC}$

FMR1

ChrX:146990500-147005000 (14.5kb)

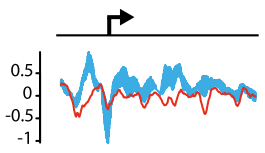

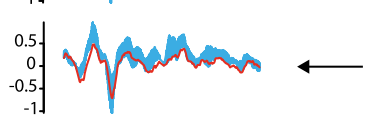

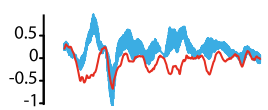

$\left.\begin{array}{r}0.5 \\ 0.5 \\ -0.5 \\ -1\end{array}\right]$ Arimonom
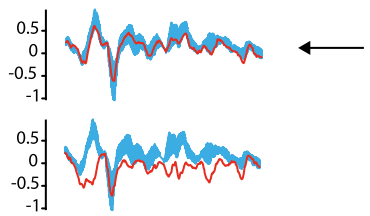

$\left.\begin{array}{r}0.5 \\ 0.5 \\ -0.5 \\ -1\end{array}\right]$ Anwanom

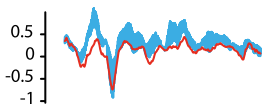

C

$5 \mathrm{mC}$ Pyrosequencing
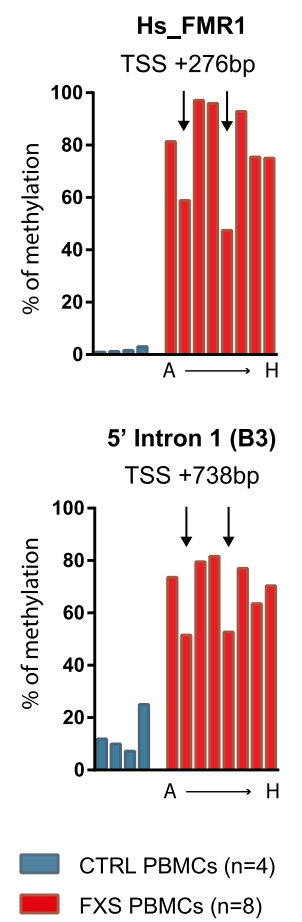

Fig. 2 (See legend on next page.) 


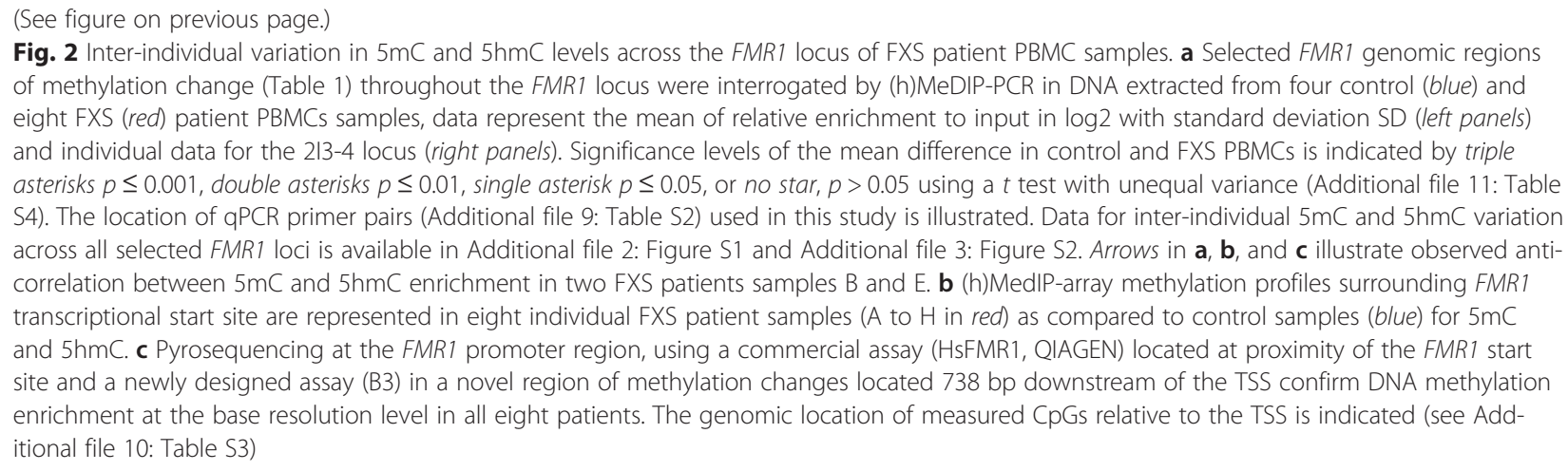

patient) and one healthy control neonatal fibroblast cell line (BJ1) (Fig. 3). $5 \mathrm{mC}$ and $5 \mathrm{hmC}$ (h)MeDIP assays were also deployed to compare chromatin changes to methylation perturbations along the FMR1 locus. (h)MeDIP and ChIP inputs and IP-enriched fractions were labeled and applied onto the custom-designed FMR1 microarray. Our data highlight extensive epigenetic remodeling across the FMR1 locus, with most significant changes taking place within regions I to V identified by (h)MeDIP in FXS PBMCs (Fig. 3). Although we cannot formally exclude that discrete regions of epigenetic changes may be related to the tissue origin and clinical background (including age) of patients, these results overall corroborate the idea that the newly identified regions correspond to bona-fide FMR1 regulatory elements perturbed in FXS samples and potentially implicated in molecular mechanisms associated to its silencing in target cells. In particular, in region II, which encompasses a region surrounding the TSS, the DNA hypermethylation was found associated with extensive change in most of the assayed marks, including decreased H3K9me2 (loss of boundary region), decreased active marks (H3K4me2, H3K9ac, H4K16ac, H4K20me1), and massive enrichment for the constitutive heterochromatin marks H3K9me3 and H4K20me3. No apparent change in H3K27me3 was detected at the TSS. Broad epigenetic landscape changes were also detected within FMR1 gene body; some marks changed throughout the gene body (e.g., H3K36me3), with most changes detected at the level of the first intron (region III) and between introns 14 and 15 (within region IV). Overall, this configuration represents a local epigenetic switch from euchromatin to heterochromatin, consistent with transcriptional gene repression. Contrary to the TSS, we found decreased methylation $(5 \mathrm{mC})$ in intragenic regions III and IV. Elevated gene body DNA methylation was previously reported to prevent spurious transcription within the gene body of active genes [38]. Loss of intragenic DNA methylation is thus consistent with FMR1 epigenetic silencing. In contrast to FXS PBMCs, no apparent change in $5 \mathrm{hmC}$ (low both in control and FXS cells) was observed in the gene body in FXS fibroblasts, suggesting cell-type (and transcriptional state)-specific differences in the distribution and levels of this mark. Finally, epigenetic perturbations were observed in regions upstream and downstream of FMR1 coding region (region I and region V, respectively) highlighting potential novel FMR1 regulatory regions.

To validate the microarray-based epigenetic landscape data obtained by ChIP-array, quantitative polymerase chain reaction (qPCR) assays were run over the region surrounding the TSS using ChIP and input material used for arrays. The results, illustrated in Additional file 4: Figure S3 confirm reduced enrichment for active marks (H3K4me2, H3K9ac, H4K16ac) throughout the TSS region and show increased association of several repressive marks (H4K20me1, H4K20me3, H3K9me3), overall recapitulating array-based data.

To further investigate epigenetic changes and pathways associated with FMR1 silencing in FXS PBMCs, and based on Coriell fibroblast ChIP-array data, nativeChIP assays using antibodies for histone PTMs, associated with and contributing to transcriptional gene repression (H3K9me2, H3K9me3) and gene activation (H3K4me2, H4K20me1), were carried out on fractionated chromatin from eight clinical FXS and three control PBMC samples. ChIP-enriched and input fractions were profiled by qPCR using assays designed at FMR1 genomic regions displaying epigenetic changes in FXS fibroblasts and PBMCs (Fig. 4). Consistent with FXS fibroblast ChIP-array data, we found extensive epigenetic remodeling of $\mathrm{H} 3 \mathrm{~K} 4 \mathrm{me} 2$ at regions II and III and of H3K9me3 and H4K20me1 largely encompassing the FMR1 coding region. Regions outside the FMR1 coding region were also perturbed at the chromatin level, highlighting epigenetic changes that may account for regulatory or structurally important regions for the regulation of the FMR1 locus. A selection of control genomic loci (RPL19, CDX2, OCT4) did not display changes in the enrichment of any of the marks tested in FXS cells (Additional file 5: Figure S4). Overall, our data reveal a FMR1 locus-wide repressive epigenetic switch and highlight unprecedented epigenetic marks and pathways that 


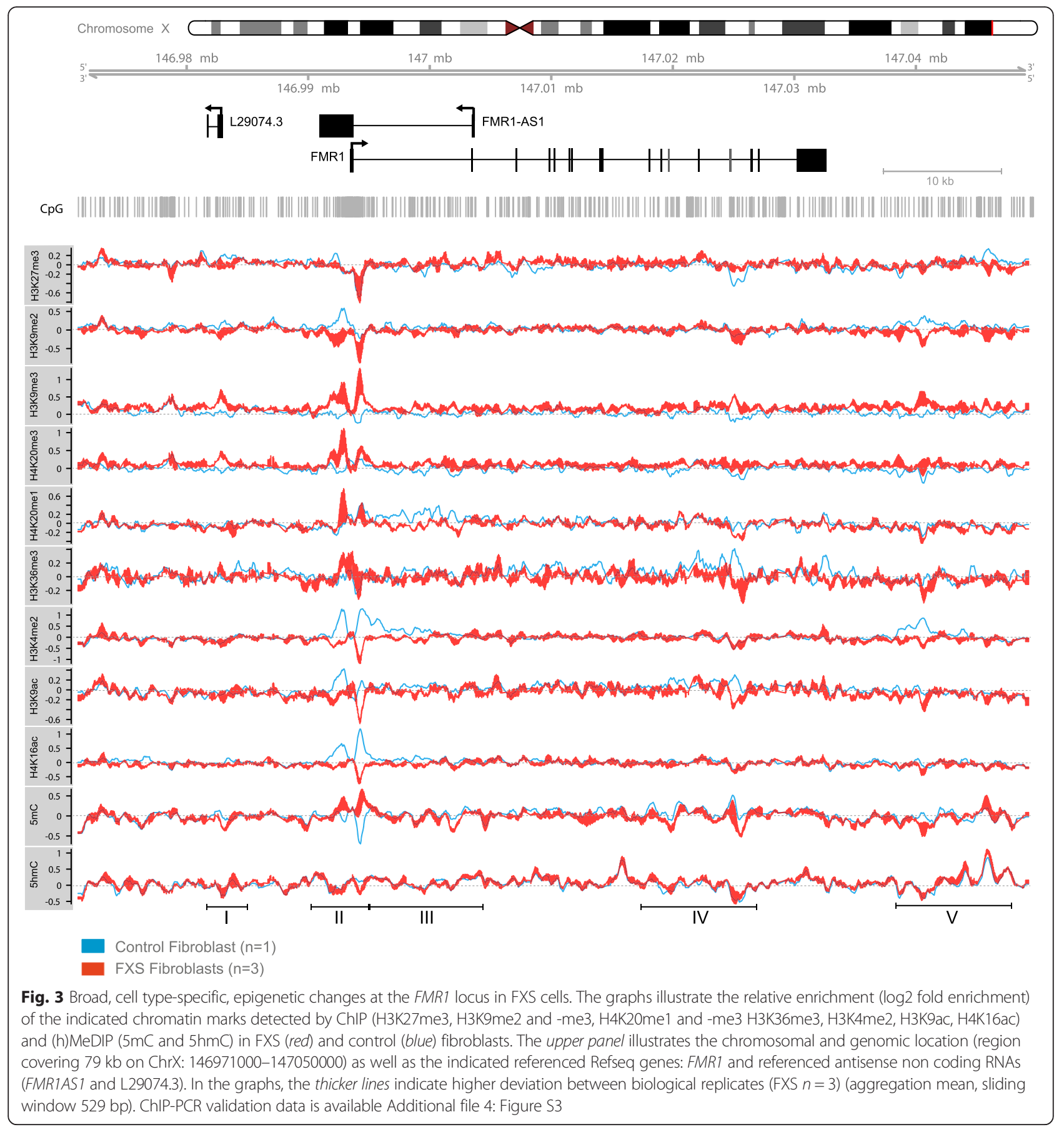

may contribute to initiating and/or maintained FMR1 transcriptional silencing in FXS cells.

\section{Combined $5 \mathrm{mC}, 5 \mathrm{hmC}$, and histone PTM profiling} enhances the molecular and functional characterization of FXS patient samples

We next investigated molecular relationship between FMR1 transcriptional expression levels, DNA methylation and hydroxymethylation as well as individual histones PTMs across the interrogated FMR1 loci in PBMC FXS patient samples (Fig. 5a, Additional file 6: Table S5). At the region surrounding the TSS (measured with assays 3C1-2, 2I3-4, and 3C5-6, as well as by the pyrosequencing assays HsFMR1 and B3), we found overall expected molecular interactions, characterizing $5 \mathrm{mC}$ and $\mathrm{H} 3 \mathrm{~K} 9 \mathrm{me} 3$ as repressive heterochromatic marks and $5 \mathrm{hmC}, \mathrm{H} 3 \mathrm{~K} 9 \mathrm{me} 2$, and $\mathrm{H} 4 \mathrm{~K} 20 \mathrm{me} 1$ as marks associated with an open euchromatic chromatin configuration and 

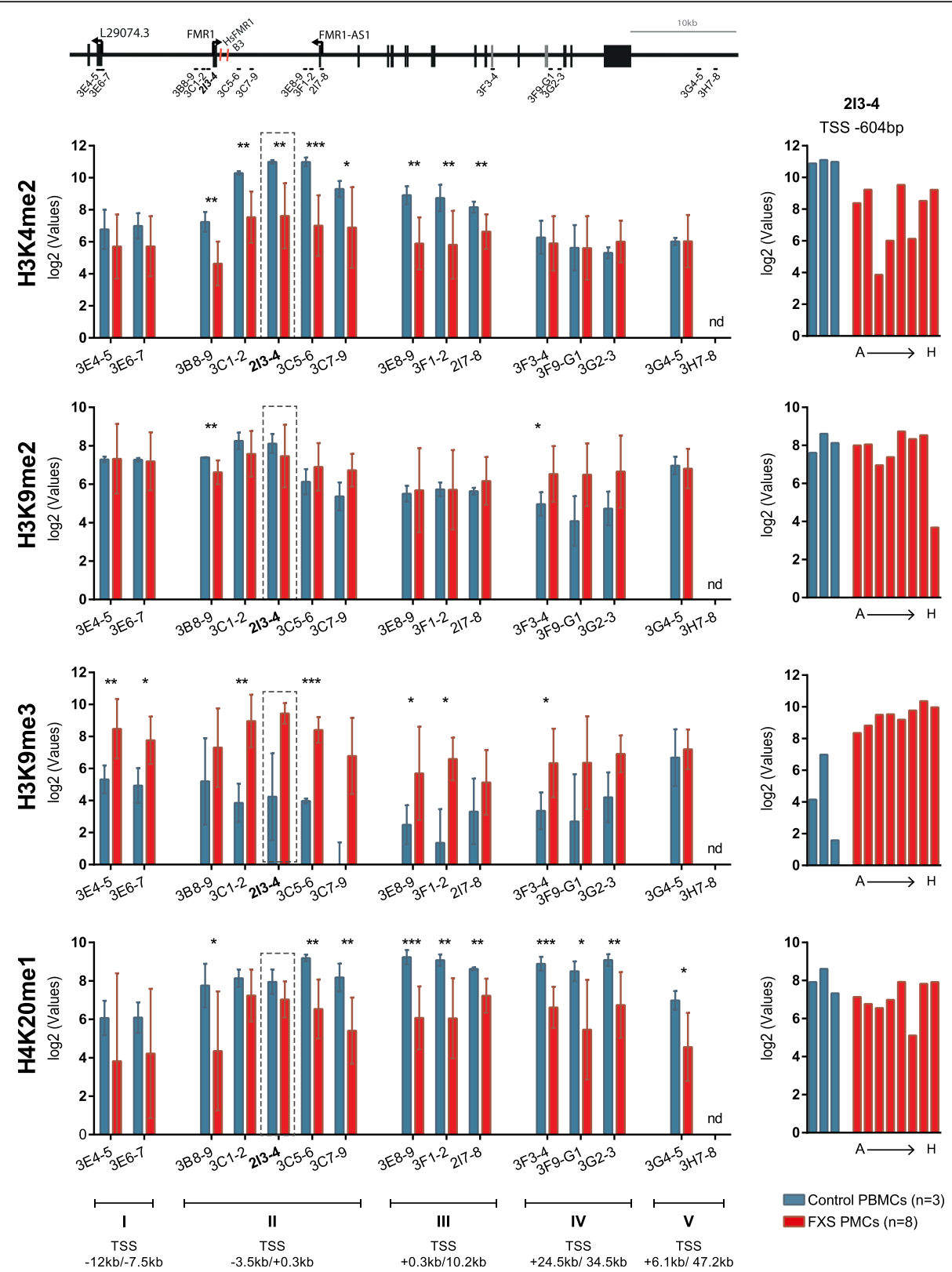

Fig. 4 Repressive epigenetic switch spanning entire FMR1 locus in FXS PBMCs. Relative ChIP-qPCR enrichment of the indicated chromatin histone post-translational modifications (H3K4me2, H3K9me2, H3K9me3, and H4K20me1) in three control (blue) and eight (red) patients samples (A to H, as in Fig. 2). Data represent the mean of relative enrichment to input in log2 with standard deviation SD (left panels). Significance levels of the mean difference in control and FXS PBMCs is indicated by triple asterisks $p \leq 0.001$, double asterisks $p \leq 0.01$, single asterisk $p \leq 0.05$, or no star $p>0.05$ using a $t$ test with unequal variance (Additional file 11: Table S4). The bar graphs on the right hand-side represents individual patient data for the indicated marks in region 2/3-4 located in the first intron of the FMR1 gene. The upper panel illustrates the FMR1 locus organization with pyrosequencing (HsFMR1 and B3) as well as PCR assays locations (listed in Additional file 1: Table S1 and Additional file 9: Table S2)

clustering the eight patients in sub-groups of molecular behavior at the TSS (Fig. 5a). Linear regression analyses between FMR1 mRNA expression levels and $5 \mathrm{mC} / 5 \mathrm{hmC}$ MeDIP enrichment at the TSS confirms the functional antagonism between these two DNA modifications at least at the TSS (Fig. 5b, c). Interestingly, we did not detect significant $5 \mathrm{mC}$ and $5 \mathrm{hmC}$ antagonism, at least as measured by enrichment-based method, away from the TSS regions of the FMR1 locus, which is consistent with the limited observed changes in $5 \mathrm{mC}$ levels outside of the FMR1 TSS by MeDIP-qPCR (Fig. 2a, Additional file 2: Figure S1A). To further explore the functional interactions between the different epigenetic pathways at the different interrogated loci, we next ran 


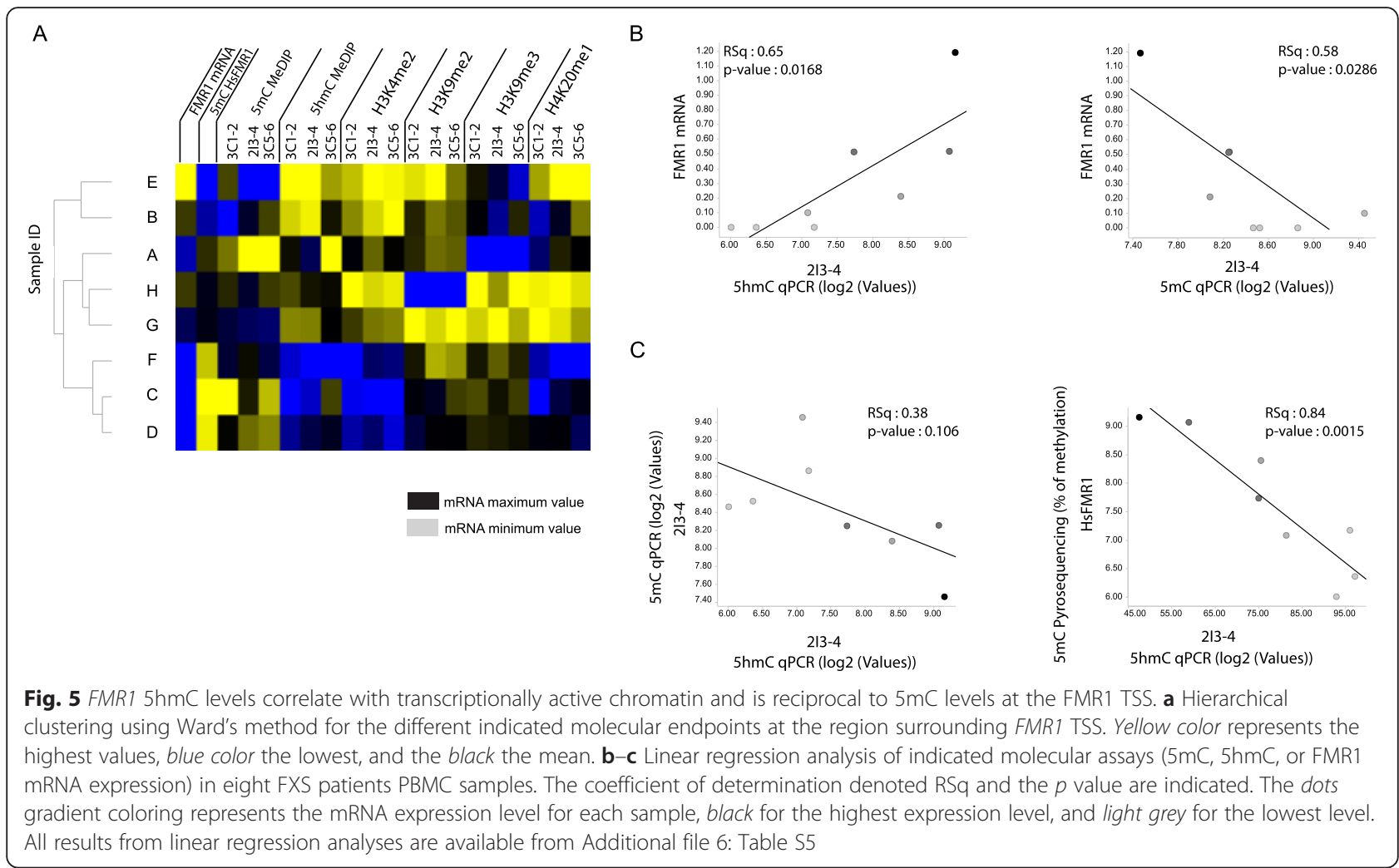

linear regression analyses using all available molecular profiling data (Additional file 1: Table S1) providing a matrix of linear correlation data (Additional file 6: Table S5). This data confirms functional antagonism between $5 \mathrm{mC}$ and $5 \mathrm{hmC}$ at the TSS with a number of assays and identifies novel potential cross-locus molecular correlations between these two cytosine modifications. Investigating the correlation between either $5 \mathrm{mC}$ or $5 \mathrm{hmC}$ and all interrogated histone PTMs highlighted significant functional correlations at heterologous FMR1 regions (illustrated Additional file 7: Figure S5). We speculate that such interactions might reflect distant functional interactions between epigenetic marks/pathways, a hypothesis that will require further mechanistic investigations in larger cohorts and deployment of appropriate chromatin configuration assays. No significant correlation between histone PTM or $5 \mathrm{mC} / 5 \mathrm{hmC}$ and the age of patients could be found in this study (not shown). Overall, our data identifies novel potential regulatory interactions within the broad FMR1 locus and demonstrate negative correlation between $5 \mathrm{mC}$ and $5 \mathrm{hmC}$ at the TSS.

\section{FMR1 methylation and hydroxymethylation are significantly correlated with $A B C$ scores in male FXS patients}

It was reported that the severity of FXS phenotypes can be influenced by the FMR1 methylation status or the magnitude of the FMRP deficit $[2,19]$. We used linear regression analyses to illustrate the relationship between $5 \mathrm{mC}$ (pyrosequencing at TSS and MeDIP-qPCR across the FMR1 locus) and 5hmC (hMeDIP-qPCR) data to the available Aberrant Behavioral Checklist-Community Edition (ABC-C score) [39] for the eight clinical study patient samples (Additional file 8: Table S6). Our analyses using TSS proximal quantitative assays (HsFMR1 and B3) confirm reported correlation between $5 \mathrm{mC}$ and clinical severity (e.g., HsFMR1 vs ABC: Rsq $0.46 p$ value 0.0644-Fig. 6b, Additional file 8: Table S6). Interrogating all assays within regions $\mathrm{I}$ to $\mathrm{V}$, we find regionspecific (anti)correlations between FMR1 methylation and $\mathrm{ABC}$ scores (Fig. 6c), particularly significant in regions III (Rsq $0.76 p$ value 0.005 for assay 3E8-9) and region IV (Rsq $0.71 p$ value 0.008 for assay 3F3-4). Consistent with significant levels of $5 \mathrm{hmC}$ changes and inter-individual variability in measured $5 \mathrm{hmC}$ levels, we observed a significant inverse correlation between $5 \mathrm{hmC}$ and $\mathrm{ABC}-\mathrm{C}$ scores for selected hMeDIP-PCR assays (Fig. 6d) across most regions of FMR1 epigenetic changes, particularly in regions II, III, and V. No significant correlations were made with the histone PTMs data (Additional file 8: Table S6). These data altogether confirm the utility of $5 \mathrm{mC}$ to predict FXS disease severity and demonstrate that $5 \mathrm{hmC}$ measurements within the FMR1 locus may be equally indicative of the disease 


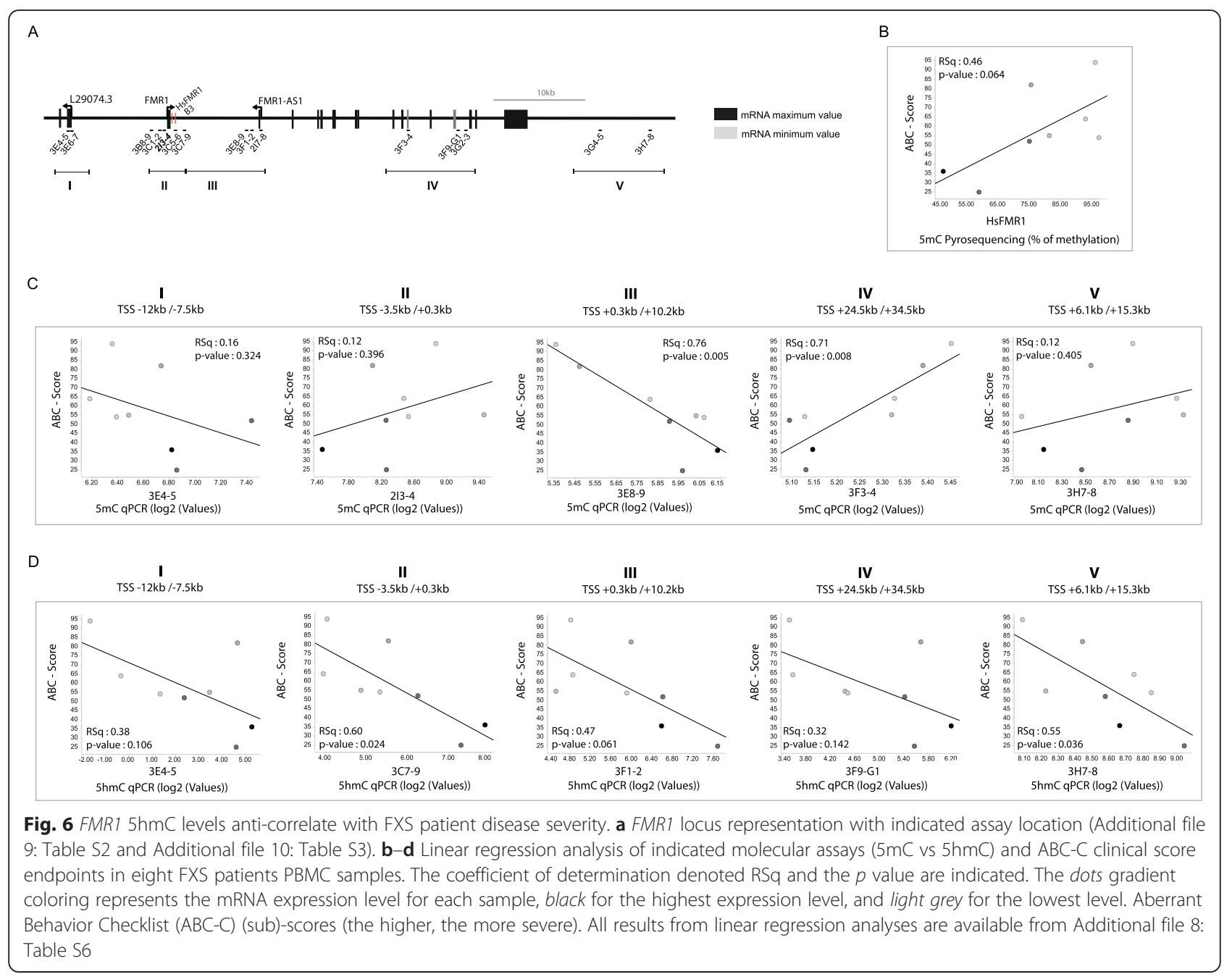

severity. The combined measurement of $5 \mathrm{mC}$ and $5 \mathrm{hmC}$ from single patient individuals may thus significantly enhance patient stratification.

\section{Discussion}

We report the identification of novel FMR1 regions of chromatin and (hydroxy)-methylation ( $5 \mathrm{mC}$ and $5 \mathrm{hmC}$ ) perturbations associated with FMR1 epigenetic silencing in FXS patient blood-derived (PBMC) samples. The genomic regions of these epigenetic changes were consistent across individual patient samples, strengthening their functional relevance for FMR1 gene regulation. FMR1 locus-specific assays for selected epigenetic marks revealed inter-individual quantitative differences in FXS patients that may be related to FMR1 locus expression and disease severity. We have integrated histone posttranslational modifications, DNA (hydroxy)-methylation, FMR1 gene expression data, and clinical severity data to identify new molecular and functional links between molecular and clinical features. In particular, we have established $5 \mathrm{hmC}$ and $\mathrm{H} 4 \mathrm{~K} 20 \mathrm{me} 1$ as novel epigenetic marks/pathways whose loss is associated with FMR1 epigenetic silencing in FXS cells, providing new opportunities for enhanced molecular stratification of FXS patients beyond the existing CGG repeat length and DNA methylation assessments.

\section{FMR1 locus regulation, beyond the transcription start site region}

While the region surrounding the FMR1 TSS (promoter/ $\mathrm{CpG}$ island and upstream part of the first intron) was previously reported to show epigenetic changes in FXS [21], we report the identification of several new regions of epigenetic changes within and flanking the FMR1 coding region. The identification of epigenetic changes outside of the FMR1 coding region suggests the presence of novel structural or regulatory regions (e.g., enhancer) regulating the expression of either FMR1 or non-coding RNA 
variants within the FMR1 locus, an observation that warrants further functional characterization. Among the broad changes taking place in FMR1 gene body, three regions are of particular interest. The region surrounding the FMR1 TSS where DNA hypermethylation is accompanied by a heterochromatin switch with a decrease of the active histones marks H3K4me2/H4K20me1 and an enrichment of the repressive marks, mainly $\mathrm{H} 3 \mathrm{~K} 9 \mathrm{me} 3$ and H3K9me2. The 5' part of the first intron of FMR1 is of interest as it is characterized by a lower CpG density as compared to the promoter and as previously reported by Godler et al. [21]; it is likely participating to the suppression of FMR1 gene expression as a consequence of CGG repeat expansion. The genomic region surrounding the referenced FMR1AS antisense RNA TSS and the alternative-splicing rich region located between introns 13 and 16 (reported to contribute the diversity of the FMR1 isoforms [40-42]) represent two additional sites of robust epigenetic changes. Interestingly, both regions represent sites of decreased $5 \mathrm{mC}$ levels, particularly evident from fibroblast profiling data. Although it is known that the methylation of DNA at the promoter suppresses gene expression, the role of DNA methylation in gene bodies is unclear [43]. Recent data support a major role for intragenic methylation in regulating cell context-specific alternative promoters in gene bodies [38]. Hypermethylation of FMR1 gene body in control fibroblasts may thus ensure the integrity of the FMR1 mRNA transcript(s) and avoid spurious transcription of this transcriptionally active locus. In the absence of transcription in FXS fibroblast cells, the normal regulation of FMR1 is perturbed and intragenic regions not labeled for hypermethylation, accounting for differential methylation in control and FXS fibroblasts. Overall, FMR1 flanking and intragenic regions of differential methylation/chromatin structure highlight novel regulatory features of FMR1 regulation, providing new insights into FMR1 gene regulation in normal, healthy control cells.

\section{Novel epigenetic pathways associated to FMR1 epigenetic regulation}

We report using hMeDIP-array/PCR that the promoter/intron 1 region of active $F M R 1$ is enriched in $5 \mathrm{hmC}$. Previous bisulfite sequencing analyses of the FMR1 promoter $\mathrm{CpG}$ island in normal individuals have consistently reported largely unmethylated DNA sequences spanning from the promoter region up to a boundary region located at a site between 650 and 800 nucleotides upstream of the CGG repeat in the first exon of the human FMR1 gene [44]. As bisulfite sequencing does not distinguish $5 \mathrm{mC}$ and $5 \mathrm{hmC}$, we propose that only selected cytosines may be hydroxymethylated within healthy control FMR1 promoter. $5 \mathrm{hmC}$ is catalyzed by the TET family of proteins [27] suggesting a role for this pathway in the normal regulation of FMR1. 5hmC is believed to both represent an epigenetic mark of its own as well as contribute to active DNA demethylation, possibly providing protection against aberrant FMR1 promoter, $\mathrm{CpG}$ island and CGG repeats methylation in healthy individuals (5-50 CGG repeats). MeCP2 was one of the first proteins identified to bind to $5 \mathrm{hmC}$ [32]. While MeCP2 is traditionally associated with gene repression through its binding to $5 \mathrm{mC}$ and recruitment of a co-repressor complex [45], it was shown to regulate gene activation in the brain upon binding to $5 \mathrm{hmC}$, an interaction lost through MeCP2 point mutations in Rett syndrome patients [32, 45]. Differential $5 \mathrm{hmC}$ levels detected by epigenomic profiling suggest a role for this mark in the normal regulation of FMR1 gene expression in healthy cells. Interestingly, changes in $5 \mathrm{hmC}$ were previously observed during cerebellum development at genes regulated by the FMRP protein as well as at many genes linked to autism [46], thus reinforcing the importance of a TET-mediated $5 \mathrm{hmC}$ epigenetic pathway in normal and pathological regulation of FMR1.

Histone H4 Lys 20 mono-methylation (H4K20me1) is also affected in FXS cells. This epigenetic mark has been implicated in the regulation of diverse processes ranging from the DNA damage response, mitotic condensation, and DNA replication to gene regulation. PR-Set7/Set8/ KMT5a is the sole enzyme that catalyzes H4K20me1 $[47,48]$. Together, the identification of $5 \mathrm{hmC}$ and H4K20me1 enrichment at FMR1 in normal individuals highlights novel pathways whose deregulation upon CGG repeat expansion might contribute to FMR1 silencing and FXS physiopathology. The analyses presented here were performed in FXS fibroblasts and PBMC samples, both representing surrogate tissues for this neurological disorder. PBMCs contain an array of different blood cell types; the fibroblasts used in this study also originate from different tissues and from patients of different ages, all representing potential confounding factors when investigating epigenetic differences at the analyzed loci. An additional potential limitation relates to the relatively small sample size in these analyses (blood $n=4 / 8$ controls/cases and fibroblasts $n=1 / 3$ controls/cases). We thus cannot formally exclude cell-type and age-specific contributions to blood- and fibroblastderived chromatin profiling data and future validation of key loci in sorted/purified cell populations from larger cohorts of healthy volunteer, and patient samples may be warranted to further explore the specificity of novel DNA methylation markers for FXS. In addition, to better understand the mechanisms associated to FMR1 silencing in the target tissue and cells, it will also be important to investigate the epigenetic landscape of the FMR1 locus in healthy and FXS brain samples. 


\section{Novel potential biomarkers for FXS diagnosis and drug response}

The methylation status of $F M R 1$ promoter/upstream intron 1 has been significantly correlated with the clinical phenotype of FXS patients [5, 16-19]. We hypothesized that additional epigenetic biomarkers within the FMR1 locus may enhance the development of novel clinical biomarkers for FXS disease states as well as support the discovery of novel mechanism-based therapeutic targets. Whilst $5 \mathrm{mC}$ measurement at the FMR1 promoter can detect full-mutated/hypermethylated FMR1 alleles in a mosaic cell population, we propose that the measurement of $5 \mathrm{hmC}$ (and other novel epigenetic features of FMR1 epigenetic activation) may help detect the unmethylated (pre- and full-mutated) alleles within a mosaic population.

\section{Conclusions}

This in-depth analysis of the FMR1 locus epigenetic landscape in full-mutation FXS patient samples identifies unprecedented regions of chromatin modifications that are characteristic of a broad FMR1 repressive epigenetic switch. Importantly, decreased levels of 5-hydroxymethylation $(5 \mathrm{hmC})$, a recently rediscovered epigenetic mark, correlate with FXS patient disease status. We propose that the combined measurement of $5 \mathrm{mC}$ and $5 \mathrm{hmC}$ from single patient individuals may provide novel diagnostic and therapeutic opportunities for FXS syndrome.

\section{Methods}

\section{Clinical specimens}

For this study, purified PBMC samples from eight fragile X patients were used. Subjects were male, aged 12-45 years (inclusive), with a confirmed diagnosis of FXS based on genetic sequencing results (full mutation, >200 CGG repeats). They were required to have a Clinical Global Impressions of Severity (CGI-S) score of $\geq 4$ (moderately ill) and a score of $\geq 20$ on the $A B C-C$ scale (at screening). The study protocol and all amendments were reviewed by the Independent Ethics Committee for the study center. The study was conducted according to the ethical principles of the Declaration of Helsinki. Informed written consent was obtained from each patient or parent/legal guardian before randomization. PBMCs were purified from blood using $8 \mathrm{~mL}$ capacity PBMC separator tubes (BD Vacutainer CPT, $\mathrm{BD})$. Healthy control samples were obtained from Bioreclamation $(n=4$, for hMeDIP) and from consented voluntary donors $(n=3$, for ChIP). GM05848 fibroblasts from a 4year-old fragile X patient, GM07072 fetal lung fibroblasts from 22-week-old fetus with a fragile mutation, and GM09497 fibroblasts from a 28-year-old fragile X patient, from Coriell Institute for Medical Research were grown in D-MEM supplemented with $15 \% \mathrm{FBS}$, penicillin/streptomycin, 2-mercaptoethanol (0.1 $\mathrm{mM})$, and sodium pyruvate.
The ATCC BJ1 neonatal fibroblast cell line used as control was cultured in the same condition.

\section{FMR1 gene expression assays}

FMR1 mRNA expression levels in the blood were measured by quantitative real-time polymerase chain reaction (qRT-PCR); $500 \mathrm{ng}$ of total RNA isolated from the blood samples collected in PAXgene tubes was reverse transcribed to cDNA using random hexamers and the high-capacity cDNA reverse transcription kit with RNAse inhibitor according to the manufacturer's procedure (Applied Biosystems, Foster City, CA). qPCR was performed using the ABI PRISM ${ }^{\circ} 7900 \mathrm{HT}$ Sequence Detection System (Applied Biosystem). The following TaqMan assays obtained from Applied Biosystems were used: FMR1: Hs00924544_m1; actin B (ACTB): Hs99999903_m1; beta-glucuronidase (GUSB): Hs99999908_m1. All samples were processed in triplicate with a 25-ng cDNA (total RNA equivalent) for $F M R 1$ and 10-ng cDNA (total RNA equivalent) for reference gene assays $(A C T B, G U S B)$. The qPCR consisted of one step at $50{ }^{\circ} \mathrm{C}$ for $2 \mathrm{~min}$, one denaturing step at $95^{\circ} \mathrm{C}$ for $10 \mathrm{~min}$ followed by 40 cycles of melting $\left(15 \mathrm{~s}\right.$ at $\left.95^{\circ} \mathrm{C}\right)$, and annealing/extension $\left(1 \mathrm{~min}\right.$ at $\left.60{ }^{\circ} \mathrm{C}\right)$. To correct for any variation in mRNA content and enzymatic efficiencies, FMR1 gene expression levels were normalized to the values of the most stable reference genes, ACTB (actin beta) and GUSB (glucuronidase beta). The data is presented as normalized relative quantity (NRQ). A Cq $(\mathrm{Ct})$ value $>38$ was considered to be the background of the assay.

\section{(Hydroxy)methylated DNA immunoprecipitation}

Genomic DNA was prepared by overnight proteinase K (pK) treatment in lysis buffer $(10 \mathrm{mM}$ Tris- $\mathrm{HCl} \mathrm{pH} 8.0$, 50 mM EDTA pH 8.0, $100 \mathrm{mM} \mathrm{NaCl}, 0.5 \%$ SDS), phenol-chloroform extraction, ethanol precipitation, and RNaseA digestion. Genomic DNA was sonicated (Bioruptor, Diagenode) to produce random fragments ranging in size from 300 to $1000 \mathrm{bp}$ and $2.5 \mu \mathrm{g}$ of fragmented DNA was used for a standard hMeDIP assay. DNA was denatured for $10 \mathrm{~min}$ at $95{ }^{\circ} \mathrm{C}$ and immunoprecipitated for $3 \mathrm{~h}$ at $4{ }^{\circ} \mathrm{C}$ with $15 \mu \mathrm{l}$ of monoclonal antibody against 5-methylcytidine (BI-MECY-1000, Eurogentec) (MeDIP) or with $1 \mu \mathrm{l}$ of a rabbit polyclonal antibody against 5-hydroxymethylcytosine (\#39769, active Motif) (hMeDIP) in a final volume of $500 \mu$ l IP buffer $(10 \mathrm{mM}$ sodium phosphate ( $\mathrm{pH} 7.0), 140 \mathrm{mM} \mathrm{NaCl}$, $0.05 \%$ Triton X-100). The mixture was incubated with $40 \mu \mathrm{l}$ magnetic beads (MeDIP: Dynabeads M-280 Sheep anti-mouse IgG (Invitrogen) for $2 \mathrm{~h}$ at $4{ }^{\circ} \mathrm{C} / \mathrm{hMeDIP}$ : Dynabeads Protein G (\#100.03D, Invitrogen) for $1 \mathrm{~h}$ at $4{ }^{\circ} \mathrm{C}$ ) and washed three times with $1 \mathrm{ml}$ of IP buffer. Beads were subsequently treated with proteinase $\mathrm{K}$ for $3 \mathrm{~h}$ 
at $50{ }^{\circ} \mathrm{C}$ and the methylated DNA recovered by phenolchloroform extraction followed by ethanol precipitation. For microarray analysis, $50 \mathrm{ng}$ of input DNA and 1/2 (h)MeDIP-enriched DNA was amplified using WGA2: GenomePlex Complete Whole Genome Amplification kit (Sigma). Amplified DNA was used for real-time qPCR quantification and sent to Roche Nimblegen (Madison, USA) for Cy3 and Cy5 labeling and hybridization on $12 \times$ $135 \mathrm{k}$ NimbleGen custom arrays.

\section{N-ChIP}

Native chromatin immunoprecipitation (N-ChIP) protocol was based on a published protocol [49] with some modifications. Aliquots of 5 million (10 million for Fibroblasts) cells were thawed on ice and resuspended in $150 \mu \mathrm{l}(250 \mu \mathrm{l}$ fibroblasts) of buffer 1 (0.3 M sucrose, $15 \mathrm{mM}$ Tris $(\mathrm{pH} 7.5), 60 \mathrm{mM} \mathrm{KCl}, 15 \mathrm{mM} \mathrm{NaCl}, 5 \mathrm{mM} \mathrm{MgCl}$, $0.1 \mathrm{mM}$ EGTA); $150 \mu \mathrm{l}$ (250 $\mu$ l fibroblasts) of buffer 1 with detergent (buffer1 including $0.5 \mathrm{mM}$ DTT, $0.5 \%$ Igepal, and $1 \%$ DOC) were added followed by an incubation on ice for $10 \mathrm{~min}$, and $300 \mu \mathrm{l}(500 \mu \mathrm{l}$ fibroblasts $)$ of MNase buffer (0.3 M Sucrose, $85 \mathrm{mM}$ Tris, $3 \mathrm{mM}$ $\mathrm{MgCl} 2,2 \mathrm{mM} \mathrm{CaCl} 2)$ containing 0.4 U MNase (0.64 U fibroblasts) (Sigma) were added to each tube. Digestion mixes were incubated at $28{ }^{\circ} \mathrm{C}$ using a thermomixer (Eppendorf) for $8 \mathrm{~min}$ (20 min fibroblasts) shaking at $500 \mathrm{rpm}$. Digestion was stopped by adding EDTA to a final concentration of $5 \mathrm{mM}$ and tubes were left at room temperature for $5 \mathrm{~min}$. Non-soluble fractions were removed by centrifugation at $18,000 \mathrm{~g}$ for $10 \mathrm{~min}$ and collecting the supernatant. The pellet was discarded; 5 to $10 \mu \mathrm{g}$ of chromatin was used for the immunoprecipitation with each antibody: H3K4me2 (07-030, Millipore), H3K9me2 (39239, Active Motif), H3K9me3 (9754S, Cell Signaling), H4K20me1 (39727, Active Motif), H4K20me3 (07-749, Millipore), H3K36me3 (Ab5090), H3K9ac (07-352, Millipore), H4K16ac (07-329, Millipore), and H3K27me3 (07-449, Millipore). The immunoprecipitation, washes, and DNA purification were done with Magna $\mathrm{ChIP}^{\mathrm{m}} \mathrm{A}$ Chromatin Immunoprecipitation Kit (Millipore \#17-610) following manufacturer's protocol. For microarray analysis, input DNA and entire ChIP DNA was amplified using WGA2: GenomePlex Complete Whole Genome Amplification kit (Sigma) according to [50]. Amplified DNA was used for real-time qPCR quantification and sent to Roche Nimblegen (Madison, USA) for Cy3 and Cy5 labeling and hybridization on $12 \times 135 \mathrm{k}$ NimbleGen custom arrays.

\section{Real-time PCR}

Real-time PCR was carried out using SYBR Green PCR Master Mix (Applied Biosystems) and using an ABI PRISM SDS 7900HT machine (Applied Biosystems). Primers are listed in Additional file 9: Table S2.

\section{FMR1 locus microarray design and data analyses}

The custom Nimblegen array consists of 27,656 different targeted (with known genomic location) 50-mer probes and 30,039 random probes (no matches in the human hg19 genome); 4117 probes cover the broader FMR1 locus, a 247-kbp region encompassing FMR1 (chrX:146,993,469147,032,647), FMR1NB (chrX: 147,062,849-147,108,187), and up to $100 \mathrm{~kb}$ of flanking genomic DNA sequence (chrX: 146,911,760-147,159,387). The array design is available upon request. $M$ values ( $\log 2$ (IP-channel/input-channel)) were calculated per targeted probe and normalized for each chip using Loess to account for non-linear dye bias. Arrays of the same IP antibody were then normalized across arrays by scaling to the same median absolute value. Targeted probes are present four times on the array (with different location), and these were summarized by averaging after normalization. All pre-processing was performed in the R-programming language; the limma package of Bioconductor was used for normalization.

\section{Pyrosequencing}

Using the EZ DNA MethylationTM Kit (ZYMO Research), 200-300 ng of genomic DNA was bisulfite treated according to the manufacturer's protocol and eluted in $30 \mu \mathrm{l}$. Pyrosequencing probes were designed with the Pyromark Design 2.0 software package (QIAGEN). Primers for PCR amplification and sequencing as well as the sequence covered by each assay are indicated in Additional file 10: Table S3; $2 \mu \mathrm{l}$ of converted DNA were used as input for PCR amplification using the AmpliTaq Gold DNA Polymerase (Applied Biosystems, N8080247), with one of two primers biotinylated. The temperature profile of the cycles was DNA polymerase activation at $95{ }^{\circ} \mathrm{C}$ for $15 \mathrm{~min}$, denaturation at $95{ }^{\circ} \mathrm{C}$ for $30 \mathrm{~s}$, annealing at $61{ }^{\circ} \mathrm{C}$ for $30 \mathrm{~s}$, and extension at $72{ }^{\circ} \mathrm{C}$ for $1 \mathrm{~min}$ for the first cycle. For the next 19 cycles, the annealing temperature was decreased by $0.5{ }^{\circ} \mathrm{C}$ per cycle. Then, 36 cycles of amplification were performed at $53{ }^{\circ} \mathrm{C}$, the final annealing temperature. The program was finished by a final elongation step at $72{ }^{\circ} \mathrm{C}$ for $10 \mathrm{~min}$. Biotinylated PCR product were then purified and immobilized onto streptavidin-coated Sepharose beads (GE Healthcare). Pyrosequencing was performed on the PyroMark Q96 MD (QIAGEN) following the manufacturer's instructions. Pyro QCpG 1.0.9 (QIAGEN) was used to quantify DNA methylation at single CpGs.

\section{Data integration and statistical analyses}

Percentage of methylation per CpG obtained by pyrosequencing was summarized by averaging the value of all CpGs per assay, $0 \%$ being unmethylated and $100 \%$ fully methylated. 5hmC MeDIP and ChIP real-time PCR data were first normalized using the efficacy of each qPCR assay. The ratio IP/input was calculated as percent of 
input and values were log base 2 transformed (adding a constant of 0.01 prior transformation) to meet the test assumptions. Significance levels of the mean difference in control and FXS PBMCs is indicated by “*:**:" $(p \leq 0.001)$, “:*:" $(p \leq 0.01), “ * "(p \leq 0.05)$, or no star $(p>0.05)$ using a $t$ test with unequal variance. The relationship between the different molecular endpoints $(5 \mathrm{mC}, 5 \mathrm{hmC}$, histones PTMs) to the clinical score (ABC-C score) [39] was assessed via ordinary linear regression analysis (including $p$ value and $R^{2}$ for goodness of fit).

\section{Additional files}

Additional file 1: Table S1. This table summarizes information for the eight FXS patients with the clinical parameters (age, ABC-C score) and molecular readouts (methylation status, number of repeats, (h)MeDIPqPCR data, ChIP-qPCR data). (XLSX 44 kb)

Additional file 2: Figure S1. Selected FMR1 genomic regions of methylation change throughout the FMR1 locus (Fig. 2a, Additional file 1: Table S1) were interrogated by MeDIP-qPCR (5mC) in DNA extracted from four control (blue) and eight FXS (red) patient PBMCs samples (A). Data represent the enrichment relative to input in individual samples. The location of qPCR primer pairs used in this study is illustrated (B). (PDF $487 \mathrm{~kb}$ )

Additional file 3: Figure S2. Selected FMR1 genomic regions of methylation change throughout the FMR1 locus (Fig. 2a, Additional file 1: Table S1) were interrogated by hMeDIP-qPCR (5hmC) in DNA extracted from four control (blue) and eight FXS (red) patient PBMCs samples (A) Data represent the enrichment relative to input in individual samples. The location of GPCR primer pairs used in this study is illustrated (B). (PDF $497 \mathrm{~kb}$ )

Additional file 4: Figure S3. Selected FMR1 and unrelated loci (APRT and OCT4) were interrogated by ChIP-PCR in healthy and FXS fibroblasts, validating Fig. 3 FMR1 microarray results. Data represent the enrichment relative to input in individual samples. (PDF $519 \mathrm{~kb}$ )

Additional file 5: Figure S4. Selected unrelated loci were interrogated by ChIP-qPCR to validate the specificity of changes observed at FMR1 in FXS patient cells. No significant change in H3K4me2, H4K2Ome1, H3K9me2, and me3 were observed at three selected loci (active locus RPL19 and two developmentally regulated loci Cdx2 and Oct4). (PDF $409 \mathrm{~kb}$ )

Additional file 6: Table S5. This table summarizes linear regression analyses ( $p$ value, RSq, R) for the indicated molecular assay $(5 \mathrm{mC}, 5 \mathrm{hmC}$, histone PTMs). (XLSX $128 \mathrm{~kb}$ )

Additional file 7: Figure S5. Linear regression analysis of the methylation $(5 \mathrm{mC})$ or hydroxymethylation $(5 \mathrm{hmC})$ assays and the different histones marks (H3K4me2, H3K9me2, H3K9me3, H4K2Ome1) in eight FXS patients PBMC samples. Graphs show the relationship with the highest coefficient of determination denoted RSq. The $p$ value is indicated, and the dots gradient coloring represents the mRNA expression level for each sample, black for the highest expression level, and light grey for the lowest level. (PDF $547 \mathrm{~kb}$ )

Additional file 8: Table S6. This table summarizes the results of linear regression analyses and the Spearman correlation ( $p$ value, RSq, R) looking at the relationship between the ABC-C score and the indicated epigenetic readouts (5mC, 5hmC, histone PTMs). (XLSX $16 \mathrm{~kb}$ )

Additional file 9: Table S2. List of the real-time qPCR assays. This table indicates the primers sequence as well as chromosome coordinates of amplicon analyzed by real-time qPCR. (DOC $37 \mathrm{~kb}$ )

Additional file 10: Table S3. List of pyrosequencing assays. This table indicates the primers sequence as well as chromosome coordinates of the amplicon analyzed by pyrosequencing. (DOC $28 \mathrm{~kb}$ )

Additional file 11: Table S4. This table summarizes the values from the statistical analyses (mean, SD, SEM, $p$ value) for each sample groups (control and FXS) for each epigenetic readout (5mC, 5hmC, histone PTMs). (XLSX $15 \mathrm{~kb})$

\section{Abbreviations}

5hmC: 5-hydroxymethylcytosine; 5mC: 5-methylcytosine; -C: Aberrant Behavior Checklist Community Scale; ChIP: chromatin immunoprecipitation; DNA: deoxyribonucleic acid; FMR1: fragile X Mental Retardation 1; FXS: fragile X Syndrome; MeDIP: methylated DNA Immunoprecipitation; mRNA: messenger ribonucleic acid; PBMC: peripheral blood mononuclear cells; PTMs: post-translational modifications; qPCR: quantitative polymerase chain reaction; TSS: transcriptional start site.

\section{Competing interests}

$\mathrm{RT}, \mathrm{SB}, \mathrm{FH}, \mathrm{BGM}, \mathrm{OG}$, and $\mathrm{JM}$ are inventors on a patent reporting predictive markers useful in the diagnosis and treatment of fragile $X$ syndrome (International Application No.: PCT/EP2013/054542).

\section{Authors' contributions}

SB carried out the molecular profiling experiments and analyses. AM and FH participated in the epigenomic profiling data analyses and visualization. RT, $S J, I R, T P, Y H, C M, F G, S D C, O G, J M$, and BGM participated in the study design, acquisition, and characterization of clinical samples. RT and SB wrote the manuscript. All authors reviewed and approved the manuscript.

\section{Acknowledgements}

We wish to thank L. Manzella, T. Zollinger, J. Decker, M. Larbaoui, E. Bertrand, and M. Marcellin (Novartis Institutes for Biomedical Research, Basel, Switzerland) for technical and analytical assistance, K. Johnson for general support, and F Pognan and A Vitobello for critical review of the manuscript. This work was supported by Novartis Pharma AG, Basel, Switzerland.

\section{Author details}

${ }^{1}$ Preclinical Safety, Translational Medicine, Novartis Institutes for Biomedical Research, Novartis Pharma AG, CH-4057 Basel, Switzerland. ${ }^{2}$ Service de Génétique Médicale, Centre Hospitalier Universitaire Vaudois, CH-1011 Lausanne, Switzerland. ${ }^{3}$ Neuroscience Translational Medicine, Novartis Institutes for Biomedical Research, Novartis Pharma AG, CH-4056 Basel, Switzerland. ${ }^{4}$ BioMarker Development, Novartis Institutes for Biomedical Research, Novartis Pharma AG, Cambridge, MA, USA. ${ }^{5}$ Clinical Diagnostics, Novartis Institutes for Biomedical Research, Novartis Pharma AG, Cambridge, MA, USA. ${ }^{6}$ Neuroscience, Novartis Institutes for Biomedical Research, Novartis Pharma AG, CH-4057 Basel, Switzerland.

Received: 27 November 2015 Accepted: 24 January 2016

Published online: 05 February 2016

\section{References}

1. Santoro MR, Bray SM, Warren ST. Molecular mechanisms of fragile X syndrome: a twenty-year perspective. Annu Rev Pathol. 2012;7:219-45. doi:10.1146/annurev-pathol-011811-132457.

2. Hagerman RJ, Berry-Kravis E, Kaufmann WE, Ono MY, Tartaglia N, Lachiewicz A, et al. Advances in the treatment of fragile $X$ syndrome. Pediatrics. 2009; 123(1):378-90. doi:10.1542/peds.2008-0317.

3. Colak D, Zaninovic N, Cohen MS, Rosenwaks Z, Yang WY, Gerhardt J, et al. Promoter-bound trinucleotide repeat mRNA drives epigenetic silencing in fragile X syndrome. Science. 2014;343(6174):1002-5. doi:10.1126/science. 1245831.

4. Fu YH, Kuhl DP, Pizzuti A, Pieretti M, Sutcliffe JS, Richards S, et al. Variation of the CGG repeat at the fragile $X$ site results in genetic instability: resolution of the Sherman paradox. Cell. 1991;67(6):1047-58.

5. Kenneson A, Zhang F, Hagedorn CH, Warren ST. Reduced FMRP and increased FMR1 transcription is proportionally associated with CGG repeat number in intermediate-length and premutation carriers. Hum Mol Genet. 2001;10(14):1449-54.

6. Tassone F, Hagerman PJ. Expression of the FMR1 gene. Cytogenet Genome Res. 2003;100(1-4):124-8. doi:72846.

7. Willemsen R, Levenga J, Oostra BA. CGG repeat in the FMR1 gene: size matters. Clin Genet. 2011;80(3):214-25. doi:10.1111/j.1399-0004.2011.01723.X.

8. Jacquemont S, Curie A, des Portes V, Torrioli MG, Berry-Kravis E, Hagerman $R J$, et al. Epigenetic modification of the FMR1 gene in fragile $X$ syndrome is 
associated with differential response to the mGluR5 antagonist AFQ056. Sci Transl Med. 2011;3(64):64ra1. doi:10.1126/scitranslmed.3001708.

9. Hansen RS, Gartler SM, Scott CR, Chen SH, Laird CD. Methylation analysis of CGG sites in the CpG island of the human FMR1 gene. Hum Mol Genet. 1992;1(8):571-8.

10. Sutcliffe JS, Nelson DL, Zhang F, Pieretti M, Caskey CT, Saxe D, et al. DNA methylation represses FMR-1 transcription in fragile $X$ syndrome. Hum Mol Genet. 1992;1(6):397-400.

11. Bell MV, Hirst MC, Nakahori Y, MacKinnon RN, Roche A, Flint TJ, et al. Physical mapping across the fragile $X$ : hypermethylation and clinical expression of the fragile X syndrome. Cell. 1991;64(4):861-6.

12. Pietrobono R, Tabolacci E, Zalfa F, Zito I, Terracciano A, Moscato U, et al. Molecular dissection of the events leading to inactivation of the FMR1 gene. Hum Mol Genet. 2005;14(2):267-77. doi:10.1093/hmg/ ddi024.

13. Coffee B, Zhang F, Ceman S, Warren ST, Reines D. Histone modifications depict an aberrantly heterochromatinized FMR1 gene in fragile $X$ syndrome. Am J Hum Genet. 2002;71(4):923-32. doi:10.1086/342931.

14. Tabolacci E, Neri G. Epigenetic modifications of the FMR1 gene. Methods Mol Biol. 2013;1010:141-53. doi:10.1007/978-1-62703-411-1_10.

15. Kumari D, Usdin K. The distribution of repressive histone modifications on silenced FMR1 alleles provides clues to the mechanism of gene silencing in fragile X syndrome. Hum Mol Genet. 2010;19(23):4634-42. doi:10.1093/hmg/ddq394.

16. Merenstein SA, Shyu V, Sobesky WE, Staley L, Berry-Kravis E, Nelson DL, et al. Fragile $X$ syndrome in a normal IQ male with learning and emotional problems. J Am Acad Child Adolesc Psychiatry. 1994;33(9):1316-21. doi:10.1097/00004583-199411000-00014.

17. Hagerman RJ, Hull CE, Safanda JF, Carpenter I, Staley LW, O'Connor RA, et al. High functioning fragile $X$ males: demonstration of an unmethylated fully expanded FMR-1 mutation associated with protein expression. Am J Med Genet. 1994:51(4):298-308. doi:10.1002/ajmg.1320510404.

18. Loesch D, Hagerman R. Unstable mutations in the FMR1 gene and the phenotypes. Adv Exp Med Biol. 2012;769:78-114

19. Taylor AK, Safanda JF, Fall MZ, Quince C, Lang KA, Hull CE, et al. Molecular predictors of cognitive involvement in female carriers of fragile $X$ syndrome. JAMA. 1994;271(7):507-14.

20. Pretto D, Yrigollen CM, Tang HT, Williamson J, Espinal G, Iwahashi CK, et al. Clinical and molecular implications of mosaicism in FMR1 full mutations. Front Genet. 2014:5:318. doi:10.3389/fgene.2014.00318.

21. Godler DE, Tassone F, Loesch DZ, Taylor AK, Gehling F, Hagerman RJ, et al. Methylation of novel markers of fragile $X$ alleles is inversely correlated with FMRP expression and FMR1 activation ratio. Hum Mol Genet. 2010;19(8): 1618-32. doi:10.1093/hmg/ddq037.

22. Godler DE, Inaba Y, Shi EZ, Skinner C, Bui QM, Francis D, et al. Relationships between age and epi-genotype of the FMR1 exon 1/intron 1 boundary are consistent with non-random X-chromosome inactivation in FM individuals, with the selection for the unmethylated state being most significant between birth and puberty. Hum Mol Genet. 2013;22(8):1516-24. doi:10.1093/hmg/ddt002

23. Tabolacci E, Moscato U, Zalfa F, Bagni C, Chiurazzi P, Neri G. Epigenetic analysis reveals a euchromatic configuration in the FMR1 unmethylated full mutations. European journal of human genetics : EJHG. 2008;16(12):1487-98. doi:10.1038/ejhg.2008.130.

24. Tabolacci E, Pietrobono R, Moscato U, Oostra BA, Chiurazzi P, Neri G. Differential epigenetic modifications in the FMR1 gene of the fragile $X$ syndrome after reactivating pharmacological treatments. European journal of human genetics : EJHG. 2005;13(5):641-8. doi:10.1038/sj.ejhg.5201393.

25. Kriaucionis S, Heintz N. The nuclear DNA base 5-hydroxymethylcytosine is present in Purkinje neurons and the brain. Science. 2009;324(5929):929-30. doi:10.1126/science.1169786.

26. Tahiliani M, Koh KP, Shen Y, Pastor WA, Bandukwala H, Brudno Y, et al. Conversion of 5-methylcytosine to 5-hydroxymethylcytosine in mammalian DNA by MLL partner TET1. Science. 2009;324(5929):930-5. doi:10.1126/science.1170116.

27. Branco MR, Ficz G, Reik W. Uncovering the role of 5-hydroxymethylcytosine in the epigenome. Nat Rev Genet. 2012;13(1):7-13. doi:10.1038/nrg3080.

28. Szulwach KE, Li X, Li Y, Song CX, Wu H, Dai Q, et al. 5-hmC-mediated epigenetic dynamics during postnatal neurodevelopment and aging. Nat Neurosci. 2011:14(12):1607-16. doi:10.1038/nn.2959.
29. Jin SG, Wu X, Li AX, Pfeifer GP. Genomic mapping of 5hydroxymethylcytosine in the human brain. Nucleic Acids Res. 2011;39(12): 5015-24. doi:10.1093/nar/gkr120.

30. Song CX, Szulwach KE, Fu Y, Dai Q, Yi C, Li X, et al. Selective chemical labeling reveals the genome-wide distribution of 5-hydroxymethylcytosine. Nat Biotechnol. 2011;29(1):68-72. doi:10.1038/nbt.1732

31. Thomson JP, Lempiainen $H$, Hackett JA, Nestor CE, Muller A Bolognani F, et al. Non-genotoxic carcinogen exposure induces defined changes in the 5-hydroxymethylome. Genome Biol. 2012;13(10):R93. doi:10.1186/gb-2012-13-10-r93

32. Mellen M, Ayata P, Dewell S, Kriaucionis S, Heintz N. MeCP2 binds to 5hmC enriched within active genes and accessible chromatin in the nervous system. Cell. 2012;151(7):1417-30. doi:10.1016/j.cell.2012.11.022.

33. Khare T, Pai S, Koncevicius K, Pal M, Kriukiene E, Liutkeviciute Z, et al. 5-hmC in the brain is abundant in synaptic genes and shows differences at the exon-intron boundary. Nat Struct Mol Biol. 2012;19(10):1037-43. doi:10.1038/nsmb.2372.

34. Cheng Y, Bernstein A, Chen D, Jin P. 5-Hydroxymethylcytosine: a new player in brain disorders? Exp. Neurol.. 2014. doi:10.1016/j.expneurol.2014.05.008.

35. Al-Mahdawi S, Virmouni SA, Pook MA. The emerging role of 5hydroxymethylcytosine in neurodegenerative diseases. Front Neurosci. 2014:8:397. doi:10.3389/fnins.2014.00397.

36. Szulwach KE, Li X, Li Y, Song CX, Han JW, Kim S, et al. Integrating 5-hydroxymethylcytosine into the epigenomic landscape of human embryonic stem cells. PLoS Genet. 2011;7(6):e1002154. doi:10.1371/journal.pgen.1002154.

37. Kinde B, Gabel HW, Gilbert CS, Griffith EC, Greenberg ME. Reading the unique DNA methylation landscape of the brain: non-CpG methylation, hydroxymethylation, and MeCP2. Proc Natl Acad Sci U S A. 2015. doi:10.1073/pnas.1411269112.

38. Maunakea AK, Nagarajan RP, Bilenky M, Ballinger TJ, D'Souza C, Fouse SD, et al. Conserved role of intragenic DNA methylation in regulating alternative promoters. Nature. 2010:466(7303):253-7.

39. Aman MG, Burrow WH, Wolford PL. The Aberrant Behavior ChecklistCommunity: factor validity and effect of subject variables for adults in group homes. American journal of mental retardation: AJMR. 1995;100(3):283-92.

40. Xie W. Dolzhanskaya N, LaFauci G, Dobkin C, Denman RB. Tissue and developmental regulation of fragile $X$ mental retardation 1 exon 12 and 15 isoforms. Neurobiol Dis. 2009;35(1):52-62. doi:10.1016/j.nbd.2009.03.015.

41. Verkerk AJ, de Graaff E, De Boulle K, Eichler EE, Konecki DS, Reyniers E, et al. Alternative splicing in the fragile X gene FMR1. Hum Mol Genet. 1993:2(4):399-404

42. Dolzhanskaya N, Bolton DC, Denman RB. Chemical and structural probing of the N-terminal residues encoded by FMR1 exon 15 and their effect on downstream arginine methylation. Biochemistry. 2008;47(33):8491-503. doi:10.1021/bi702298f

43. Ndlovu MN, Denis H, Fuks F. Exposing the DNA methylome iceberg. Trends Biochem Sci. 2011:36(7):381-7. doi:10.1016/j.tibs.2011.03.002.

44. Naumann A, Hochstein N, Weber S, Fanning E, Doerfler W. A distinct DNA-methylation boundary in the 5'- upstream sequence of the FMR1 promoter binds nuclear proteins and is lost in fragile $X$ syndrome. Am J Hum Genet. 2009;85(5):606-16. doi:10.1016/j.ajhg.2009.09.018.

45. Guy J, Cheval H, Selfridge J, Bird A. The role of MeCP2 in the brain. Annu Rev Cell Dev Biol. 2011;27:631-52. doi:10.1146/annurev-cellbio-092910-154121.

46. Wang T, Pan Q, Lin L, Szulwach KE, Song CX, He C, et al. Genome-wide DNA hydroxymethylation changes are associated with neurodevelopmental genes in the developing human cerebellum. Hum Mol Genet. 2012;21(26):5500-10. doi:10.1093/hmg/dds394

47. Guo Y, Nady N, Qi C, Allali-Hassani A, Zhu H, Pan P, et al. Methylation-statespecific recognition of histones by the MBT repeat protein L3MBTL2. Nucleic Acids Res. 2009:37(7):2204-10. doi:10.1093/nar/gkp086.

48. Kalakonda N, Fischle W, Boccuni P, Gurvich N, Hoya-Arias R, Zhao X, et al. Histone $\mathrm{H} 4$ lysine 20 monomethylation promotes transcriptional repression by L3MBTL1. Oncogene. 2008;27(31):4293-304. doi:10.1038/onc.2008.67.

49. Umlauf D, Goto Y, Feil R. Site-specific analysis of histone methylation and acetylation. Methods Mol Biol. 2004;287:99-120.

50. O'Geen H, Nicolet CM, Blahnik K, Green R, Farnham PJ. Comparison of sample preparation methods for ChIP-chip assays. Biotechniques. 2006;41(5):577-80 